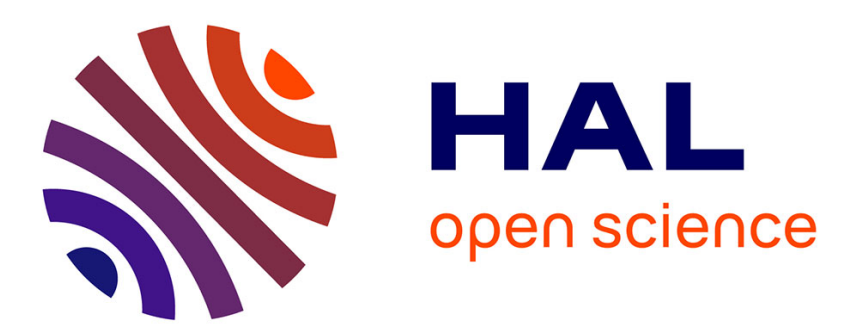

\title{
Reliability and validity of the French adaptation of the Family Relationship Index-short form in patients' with chronic kidney disease
}

Lucile Montalescot, Elodie Speyer, Karine Legrand, Carole Ayav, Christian Combe, Bénédicte Stengel, Aurélie Untas

\section{To cite this version:}

Lucile Montalescot, Elodie Speyer, Karine Legrand, Carole Ayav, Christian Combe, et al.. Reliability and validity of the French adaptation of the Family Relationship Index-short form in patients' with chronic kidney disease. Journal of Health Psychology, 2020, 10.1177/1359105320949921 . hal$03038131 \mathrm{v} 2$

\section{HAL Id: hal-03038131 \\ https://hal.science/hal-03038131v2}

Submitted on 8 Jan 2021

HAL is a multi-disciplinary open access archive for the deposit and dissemination of scientific research documents, whether they are published or not. The documents may come from teaching and research institutions in France or abroad, or from public or private research centers.
L'archive ouverte pluridisciplinaire HAL, est destinée au dépôt et à la diffusion de documents scientifiques de niveau recherche, publiés ou non, émanant des établissements d'enseignement et de recherche français ou étrangers, des laboratoires publics ou privés. 
Reliability and validity of the French adaptation of the Family Relationship Index-short form in patients' with chronic kidney disease

Lucile Montalescot ${ }^{1}$, Elodie Speyer ${ }^{2}$, Karine Legrand ${ }^{3}$, Carole Ayav ${ }^{3}$, Christian Combe ${ }^{4}$, Bénédicte Stengel ${ }^{2}$, Aurélie Untas ${ }^{1}$ on behalf of the CKD-REIN study group

${ }^{1}$ Université de Paris, LPPS, F-92100 Boulogne-Billancourt, France

${ }^{2}$ Université Paris-Saclay, Université Versailles Saint-Quentin-en-Yvelines, Université Paris-Sud, Inserm, Équipe Epidémiologie Clinique, CESP, 94807, Villejuif, France.

${ }^{3}$ Clinical Epidemiology, Inserm CIC-EC, CHU de Nancy, Vandoeuvre-lès-Nancy, France

${ }^{4}$ Service de Néphrologie Transplantation Dialyse Aphérèses, Centre Hospitalier Universitaire de Bordeaux, and Unité INSERM U1026, Bordeaux, France

\section{Authorizations}

All legal autorizations were obtained including those from the Comité consultatif sur le traitement de I'information en matière de recherche dans le domaine de la santé (CCTIRS $N^{\circ} 12.360$ ), the Commission nationale de l'informatique et des libertés (CNIL N'DR-2012-469), and from the Kremlin-Bicêtre Comité de protection des personnes (CPP N\%IDRCB 2012-A00902-41). CKD-REIN biological collection is registered in the management application of the COnservation D'Eléments du COrps Humain (CODECOCH N-2012-1624). The Institut national de la santé et de la recherche médical (Inserm) Institutional Review Board approved the study protocol (IRB00003888). ClinicalTrials.gov Identifier: NCT03381950.

\section{Acknowledgements}

We acknowledge the CKD-REIN study coordination staff for their efforts in setting up the CKDREIN cohort: Marie Metzger, Elodie Speyer, Céline Lange, Sophie Renault, Reine Ketchemin, Natalia Alencar de Pinho and all the clinical research associates.

\section{Funding}

CKD-REIN is funded by the Agence Nationale de la Recherche through the 2010 "CohortesInvestissements d'Avenir " program (ANR) and by the 2010 national Programme Hospitalier de Recherche Clinique. CKD-REIN is also supported through a public-private partnership with Amgen, Fresenius Medical Care, and GlaxoSmithKline (GSK), since 2012, Lilly France since 2013, and Otsuka Pharmaceutical since 2015, Baxter and Merck Sharp \& Dohme-Chibret (MSD France) from 2012 to 2017, Sanofi-Genzyme from 2012 to 2015, Vifor Fresenius, and AstraZeneca, since 2018.

\section{CKD-REIN study group}

ALENCAR DE PINHO Natalia, AYAV Carole, COMBE Christian, FOUQUE Denis, FRIMAT Luc, JACQUELINET Christian, LAVILLE Maurice, LIABEUF Sophie, MASSY Ziad, PASCAL Christophe, ROBINSON Bruce, STENGEL Bénédicte, SPEYER Elodie 


\section{ABSTRACT}

Objective. The Family Relationship Index (FRI) measures family cohesion, expressiveness and conflict. This study aimed to investigate its reliability and validity in patients with chronic kidney disease (CKD).

Methods. Confirmatory factor analysis was performed on 1657 patients and on subgroups according to socio-demographics, medical variables and questionnaire completion.

Results. Two items with poor saturation were excluded. The indexes indicated an acceptable fit. Reliability was especially weak for expressiveness.

Conclusion. Our results provide partial support for the use of the French-version of the FRI in patients with advanced CKD. The FRI should be used with caution, especially in certain subgroups and for the expressiveness subscale.

Keywords: chronic kidney disease; validation; family functioning; family; scale 


\section{INTRODUCTION}

The links between chronic kidney disease (CKD), patient adjustment and family functioning are complex and encompass feedback loops. CKD impacts family relations in different ways (e.g. causing worry in close others) (Smith \& Soliday, 2001). The illness affects patients as well as their family (Paschou et al., 2018). Moreover, social support, especially family support, plays an important role in patients' adjustment to chronic illness. Family support is associated with patients' outcomes, especially improved mental health, quality of life and treatment adherence (Rosland et al., 2012; Untas, Thumma, et al., 2011). Furthermore, dyadic effects have been highlighted in the literature: the characteristics of close others (e.g. burden) can influence patients' adjustment (e.g. positive affects) (Pruchno et al., 2009; Wilson-Genderson et al., 2009). Therefore, family relations are a crucial factor in patient adjustment. Adequate measures are needed to assess this variable in future studies.

Measures of family functioning can be affected by social desirability, as well as by specific situations, gender and socio-demographic variables in general (Pritchett et al., 2011; Tutty, 1995). For example, women tend to report a higher number of marital problems than men even when asked relatively objective questions (Szinovacz, 1983). Moreover, family functioning measures may not all be sensitive to the stages of the family life cycle (e.g. having children): consensus between husbands and wives is more frequent when they do not have children (Larsen \& Olson, 1990). Family functioning scales often focus on an archetypical nuclear family (e.g. a mother and a father living with their young children) (Favez, 2010). Thus, these measures could be affected by several factors such as age and if the family lives under the same roof. Moreover, a longitudinal study has highlighted changes in family functioning following renal replacement therapy (Devins et al., 1997). As disease progression seems to affect this type of variable, assessing the quality of family functioning measures according to illness stage seems relevant. In addition to CKD, the presence of another chronic illness may affect psychometric properties. For example, a diabetes diagnosis decreases family flexibility (Northam et al., 1996). Overall, this could affect the relevance of these scales in certain subgroups. However, several validation studies on family functioning scales did not investigate psychometric properties while taking into account these variables (Hoge et al., 1989; Olson, 2011; Skinner et al., 2000).

The Family Relationship Index (FRI) is a scale that belongs to the Family Environment Scale (Moos \& Moos, 2002). It has been used in various contexts to measure the quality of family relations. It is composed of three subscales: cohesion (the degree of commitment, help and support family members provide to one another), expressiveness (the extent to which family members are encouraged to express their feelings directly) and conflict (the amount of openly expressed anger among family members). The initial questionnaire comprises 27 items (Moos \& Moos, 2002) and has satisfactory 
psychometric properties (Margola et al., 2017; Untas, Rascle, et al., 2011). A shorter 12 -item version has been proposed (Kissane \& Bloch, 2002). Its French adaptation, validated across a sample of students, showed good psychometric properties (Untas, Rascle, et al., 2011). However, its validity has not been tested in patients with chronic diseases, except in cancer, for which it seems to be a good screening measure for families at risk of poor psychological outcomes (Edwards \& Clarke, 2005). An evaluation of the factor structure of this scale in different subgroups is lacking.

The aim of the present study was to assess the reliability and construct validity of the 12-item FRI (FRI12) among patients with CKD participating in the French CKD-REIN (Chronic Kidney Disease-Renal Epidemiology and Information Network) cohort study. We also assessed these properties by subgroups defined by age, gender, living condition, education level, CKD stage and diabetes, as well as on the condition of questionnaire completion (alone or with help).

\section{METHOD}

\section{Patients and study design}

The French CKD-REIN study is a prospective cohort of adult patients with stage 3-5 CKD (estimated glomerular filtration rate (eGFR) $<60 \mathrm{~mL} / \mathrm{min} / 1.73 \mathrm{~m}^{2}$ ) (i.e. global renal function of $<2 / 3$ of normal) who were not on dialysis. Patients were recruited in 2013-2016 from 40 nationally representative nephrology outpatient clinics. The details of the study protocol and patient baseline characteristics have been published elsewhere (Stengel et al., 2014, 2019). The study protocol was approved by the relevant French ethics institutions (Institut national de la santé et de la recherche médical (Inserm); IRB00003888) and has been registered at ClinicalTrials.gov (NCT03381950).

Regarding the French adaptation of the scale, a first French translator translated the scale from English to French. Then, a second English translator performed a back-translation from French to English. This process was then discussed between the two translators and the author to find the wording closest to the original meaning while keeping it easy to understand in French. The items were then pre-tested with 10 people who did not live with CKD. All items were considered clear, so no further changes were made. Examples of the translated items include: 'Les membres de notre famille s'aident et se soutiennent réellement entre eux' (cohesion), 'Les membres de notre famille gardent souvent leurs sentiments pour eux' (expressiveness), 'Dans notre famille, on se dispute beaucoup' (conflict). The entire scale in French is available upon request to the author. 


\section{Data collection}

Clinical patient-level data were collected by trained clinical research associates from patient interviews and medical records. Each enrolled patient received a patient questionnaire $(\mathrm{PQ})$ containing questions regarding socio-demographics as well as several scales, including the FRI-12. Whether patients completed the PQ alone or with help was also recorded. For this study, we chose to use the FRI-12 by offering a wider range of answer modalities. The original dichotomous format (true vs false) was changed to a 4-point Likert scale (true, quite true, quite false, false) to improve the questionnaire's sensibility.

\section{Statistical analysis}

Baseline cross-sectional data were used for the analyses. Standard descriptive statistics (means, standard deviations and frequencies) were used to report cohort characteristics and the differences between participants who provided complete responses.

Reliability was measured for each subscale in the entire sample and in subgroups: gender (men vs women); age ( $\leq 50,51-65,66-80,>80$ years); living status (alone vs with at least one relative); education level ( $\leq 9,10-12,>12$ years); CKD stage (stage 3 (eGFR $30-59 \mathrm{~mL} / \mathrm{min} / 1.73 \mathrm{~m}^{2}$ ) vs 4/5), (eGFR $<30 \mathrm{~mL} / \mathrm{min} / 1.73 \mathrm{~m}^{2}$ )); diabetes status (yes vs no); questionnaire completion (alone vs with help). We reported Cronbach's alpha and the average variance extracted (AVE). The AVE indicates the degree of convergence among items representing a latent construct (Fornell \& Larcker, 1981; McDonald, 2011). Its value should be $>0.5$ (Hair et al., 2014).

Confirmatory factor analyses were used to evaluate how well the initial three subscales measuring cohesion, expressiveness and conflict fit the data, using goodness-of-fit measures following established criteria (Hooper et al., 2008): relative chi-square (chi-square/degree of freedom) < 5; comparative fit index $(\mathrm{CFI}) \geq 0.9$; goodness of fit index $(\mathrm{GFI}) \geq 0.9$; adjusted goodness of fit $(\mathrm{AGFI}) \geq 0.9$; root mean square error of approximation (RMSEA) $\leq 0.08$ and standardized root mean square residual $(S R M R)<0.08$. We proceeded to these analyses on patients who completed the whole questionnaire.

We assessed measurement invariance across all subgroups to examine whether participants from different groups interpreted the same measure in a similar way (Chen, 2008). The four phases of measurement invariance are: configural, metric, scalar and strict invariance. Configural invariance tests whether the factor structure of a scale fits well across different groups. This requires performing a CFA on the subgroups of interest. Metric invariance tests whether the factor loadings are similar across groups. Scalar invariance examine of the item intercepts are equivalent in each group. Finally, strict invariance refers to a "situation in which measurement parameters are exactly the same across 
groups" (Van De Schoot et al., 2015). To conclude on the measurement invariance across groups, the following criteria have been established: the differences in chi-square between models should be nonsignificant (Vandenberg \& Lance, 2000).

All statistical analyses were performed using R software.

\section{Data sharing statement}

The data used in this research are restricted but can be obtained by writing to BS.

\section{RESULTS}

\section{Characteristics of the population}

Among the 3,033 patients enrolled into the CKD-REIN cohort study, 2,693 (88\%) returned the baseline $P Q$, of whom 2,615 (97\%) had no cognitive impairment, 2,042 (78\%) provided complete responses to the FRI-12 survey and 1,657 (81\%) completed the questionnaire alone. This sample was used for the following analyses. We chose to exclude patients who completed the questionnaire with help as most of them (91\%) completed it with a family member. This may induce measure bias. The mean patient age was 65.3 years (standard deviation $=12.9$ ) and $67 \%$ were men. Detailed results and comparisons between the participants who completed the whole questionnaire and those who did not are presented in Table 1 whereas comparisons between the participants who needed help to complete it and those who did not are presented in Table 2.

\section{INSERT HERE TABLE 1 and 2}

\section{Sensibility of the items and internal consistency}

The sensibilities of the items are presented in Table 3. Item 9 ('Family members sometimes get so angry they throw things') has high kurtosis and seems insufficiently sensible. For the entire sample and the subgroups, Cronbach's alphas were quite acceptable for the cohesion and conflict subscales, but were weak for the expressiveness subscale. Deleting one item did not improve these levels of internal consistency, except for expressiveness by deleting item 8 ('It is hard to "blow off steam" at home without upsetting somebody'). However, the alphas for expressiveness were especially weak for patients with $\leq 9$ years of education (Cronbach's $\alpha=0.40$ ). Importantly, none of the questionnaire subscales had an adequate AVE. These results are presented in Table 3 and in a supplementary file. 


\section{Confirmatory factor analysis}

For the entire sample, each goodness-of-fit indicator indicated an acceptable fit. Only relative chisquare was high (because of sample size). All items had acceptable factor loading, except item 8 from the expressiveness subscale (0.20). Therefore, a three-factor model without items 8 and 9 was tested. Goodness-of-fit indexes remained acceptable and was slightly increased for CFI and GFI. This model was then tested for each subgroup and showed acceptable fits. However, the subgroup of patients who completed the PQ with help showed the lowest fit indicators. The results are presented in a supplementary file.

Moreover, we tested for measurement invariance. These results are available in a supplementary file. Although configural invariance was satisfactory, scalar, strict and sometimes metric invariance were not confirmed in several multi-group comparisons. In particular, living condition showed important measurement variance.

\section{DISCUSSION}

The aim of this study was to assess the reliability and construct validity of the French version of the FRI-12 among CKD patients. The results show that the FRI-12 appears to be a valid tool for measuring family functioning, with similar properties according to various socio-demographic and medical characteristics. However, its reliability is unsatisfactory and should be assessed with caution in each population it is used with before proceeding to further analyses.

A version retaining the original factor structure of the FRI without items 8 and 9 appears more relevant than the 12-item form. Indeed, deleting both items improved the internal consistency of the expressiveness subscale without deteriorating the fit of the model. Therefore, the use of the French 11-item FRI is recommended, although the results for the expressiveness subscale should be approached with caution, as the Cronbach's alphas were quite low. Moreover, the AVE values were not satisfactory. This suggests that the scale has limited reliability. In the literature, this has been observed for the FRI subscales and might be explained by the diversity in the content of items belonging to the same factor (e.g. for expressiveness, family members keep feelings to themselves (item 2), say anything they want at home (item 5 ), tell each other about their personal problems (item 11) (Moos, 1990).

These results raise the question of the difficulty of measuring family relations, especially with selfreported questionnaires. Indeed, this method does not capture their complexity and does not evaluate how interactions take place in an ecological setting: they measure participants' representations of their family. To evaluate family relationships, multiplying the type of measures (e.g. questionnaires, 
observations of interactions), informers (i.e. different family members) and moments of inquiry (i.e. experience sampling methodology) should be the gold standard (Favez, 2010).

An important finding is that validity remained stable across the subgroups for socio-demographic and medical characteristics. Interestingly, fit was quite similar across age groups and living conditions (alone or not). If the FRI survey had been constructed for families with young children, our results suggest that it may be suitable for older peoples' families. However, although configural invariance was confirmed, other phases of measurement invariance were not. In particular, living condition and diabetes showed unsatisfactory results. This could indicate that the differences observed in family relations between participants living alone and those living with family members could be due to differences in scale properties across groups (Chan, 2011). Therefore, living condition and diabetes may affect how family functioning is measured. The respondents of these different groups may interpret some items in a conceptually different way (Putnick \& Bornstein, 2016). For example, some items may have different meanings for participants who live with family members and those who do not. In particular, some items of the FRI mention 'home' (e.g. 'family members say anything they want at home'). Qualitative studies could help examine what family cohesion, expressiveness and conflict mean in each of these groups and how their views differ. This could help improve the FRI and other measures of family functioning. Although the measurement non-invariance of the scale could be partly due to our sample size, future research should perform item-level analyses to evaluate the quality of each item (Putnick \& Bornstein, 2016). Indeed, this could help identify which items to retain, exclude and/or reword differently.

Moreover, expressiveness may be difficult to measure through self-reported scales, as it refers to interactions. We chose to retain this subscale despite its low reliability, as short and self-reported tools measuring this construct are needed. However, we advise researchers who wish to use the FRI to assess its reliability systematically, in particular for this subscale. If its reliability is too low, the expressiveness measure should be excluded from further analyses.

Despite its faults, this scale could help identify patients in need of social support and/or psychological care. If family difficulties are identified in advanced CKD patients, medical staff should be attentive to the degree of family influence on decision-making, as it could increase decision regret after renal replacement therapy initiation (Berkhout-Byrne et al., 2017).

Investigating psychometric properties across subgroups also allows the identification of populations for which the scales may not be adequate. Our results highlight that the FRI does not show satisfactory reliability or a good fit for patients with low education level, especially regarding the expressiveness subscale. This could result from difficulties in understanding some of its items. 
The present findings should be interpreted in light of the strengths and limitations of the design and conduct of our study. The major strengths include the large sample of CKD patients (>1500) and the standardization of data collection methods across all nationally representative nephrology outpatient clinics. One limitation is that these results are restricted to adults with moderate to advanced CKD who are not on dialysis or transplanted. Another limitation is that the FRI was not specifically designed for CKD patients, whose mean age is quite high compared to previous validation populations (Hoge et al., 1989; Hungerbuehler et al., 2011). Furthermore, our procedure did not include questions on which family members patients were considering when completing the scale. Future studies should include such measures and explore if it might help increase questionnaire reliability.

To conclude, this study provides only partial support for the use of the FRI in its 10-item version. Further studies should perform item-level analyses as well as identify the association of family relations with patient outcomes. 


\section{REFERENCES}

Berkhout-Byrne, N., Gaasbeek, A., Mallat, M. J. K., Rabelink, T. J., Mooijaart, S. P., Dekker, F. W., \& Van Buren, M. (2017). Regret about the decision to start dialysis : A cross-sectional Dutch national survey. Netherlands Journal of Medicine, 75(6), 225-234.

Chan, D. (2011). Advances in analytical strategies. In APA handbook of industrial and organizational psychology, Vol 1 : Building and developing the organization (p. 85-113). American Psychological Association. https://doi.org/10.1037/12169-004

Chen, F. F. (2008). What happens if we compare chopsticks with forks? The impact of making inappropriate comparisons in cross-cultural research. Journal of Personality and Social Psychology, 95(5), 1005-1018. https://doi.org/10.1037/a0013193

Devins, G. M., Hunsley, J., Mandin, H., Taub, K. J., \& Paul, L. C. (1997). The marital context of end-stage renal disease : Illness intrusiveness and perceived changes in family environment. Annals of Behavioral Medicine, 19(4), 325-332. https://doi.org/10.1007/BF02895149

Edwards, B., \& Clarke, V. (2005). The validity of the family relationships index as a screening tool for psychological risk in families of cancer patients. Psycho-Oncology, 14(7), 546-554. https://doi.org/10.1002/pon.876

Favez, N. (2010). L'examen clinique de la famille. Mardaga. https://www.cairn.info/I-examen-cliniquede-la-famille--9782804700713.htm

Fornell, C., \& Larcker, D. F. (1981). Evaluating structural equation models with unobservable variables and measurement error. Journal of Marketing Research, 18(1), 39-50. https://doi.org/10.2307/3151312

Hair, J. F., Black, W. C., Babin, B. J., \& Anderson, R. E. (Éds.). (2014). Multivariate data analysis (7. ed., Pearson new internat. ed). Pearson.

Hoge, R. D., Andrews, D. A., Faulkner, P., \& Robinson, D. (1989). The family relationship index : Validity data. Journal of Clinical Psychology, 45(6), 897-903. https://doi.org/10.1002/10974679(198911)45:6<897::AID-JCLP2270450611>3.0.CO;2-T

Hooper, D., Coughlan, J., \& Mullen, M. R. (2008). Structural Equation Modelling: Guidelines for Determining Model Fit Structural Equation Modelling: Guidelines for Determining Model Fit. The Electronic Journal of Business Research Methods, 6(1), 53-60. https://doi.org/10.1037/1082989X.12.1.58

Hungerbuehler, I., Vollrath, M. E., \& Landolt, M. A. (2011). Posttraumatic growth in mothers and fathers of children with severe illnesses. Journal of Health Psychology, 16(8), 1259-1267. https://doi.org/10.1177/1359105311405872

Kissane, D. W., \& Bloch, S. (2002). Family Focused Grief Therapy: A Model of Family Centred Care during Palliative Care and Bereavement (Open University Press).

Larsen, A., \& Olson, D. H. (1990). Capturing the complexity of family systems : Integrating family theory, family scores, and family analysis. In Family variables : Conceptualization, measurement, and use ( $\mathrm{p}$. 19-47). Sage Publications, Inc. 
Margola, D., Fenaroli, V., Sorgente, A., Lanz, M., \& Costa, G. (2017). The Family Relationships Index (FRI) : Multilevel Confirmatory Factor Analysis in an Italian Community Sample. European Journal of Psychological Assessment. https://doi.org/10.1027/1015-5759/a000427

McDonald, R. P. (2011). Test Theory : A Unified Treatment. Routledge Taylor \& Francis Group.

Moos, R. H. (1990). Conceptual and Empirical Approaches to Developing Family-Based Assessment Procedures: Resolving the Case of the Family Environment Scale. Family Process, 29(2), 199-208. https://doi.org/10.1111/j.1545-5300.1990.00199.x

Moos, R. H., \& Moos, B. S. (2002). Family environment scale manual : Development, applications, research.

Northam, E., Anderson, P., Adler, R., Werther, G., \& Warne, G. (1996). Psychosocial and Family Functioning in Children with Insulin-Dependent Diabetes at Diagnosis and One Year Later. Journal of Pediatric Psychology, 21(5), 699-717. https://doi.org/10.1093/jpepsy/21.5.699

Olson, D. (2011). FACES IV and the Circumplex Model : Validation Study. Journal of Marital and Family Therapy, 37(1), 64-80. https://doi.org/10.1111/j.1752-0606.2009.00175.x

Paschou, A., Damigos, D., Skapinakis, P., \& Siamopoulos, K. (2018). The Relationship between Burden and Depression in Spouses of Chronic Kidney Disease Patients. 2018. https://doi.org/10.1155/2018/8694168

Pritchett, R., Kemp, J., Wilson, P., Minnis, H., Bryce, G., \& Gillberg, C. (2011). Quick, simple measures of family relationships for use in clinical practice and research. A systematic review. Family Practice, 28(2), 172-187. https://doi.org/10.1093/fampra/cmq080

Pruchno, R., Wilson-Genderson, M., \& Cartwright, F. P. (2009). Depressive Symptoms and Marital Satisfaction in the Context of Chronic Disease: A Longitudinal Dyadic Analysis. Journal of Family Psychology, 23(4), 573-584. https://doi.org/10.1037/a0015878

Putnick, D. L., \& Bornstein, M. H. (2016). Measurement Invariance Conventions and Reporting : The State of the Art and Future Directions for Psychological Research. Developmental review : DR, 41, 71-90. https://doi.org/10.1016/j.dr.2016.06.004

Rosland, A.-M., Heisler, M., \& Piette, J. D. (2012). The impact of family behaviors and communication patterns on chronic illness outcomes : A systematic review. Journal of Behavioral Medicine, 35(2), 221239. https://doi.org/10.1007/s10865-011-9354-4

Skinner, H., Steinhauer, P., \& Sitarenios, G. (2000). Family Assessment Measure (FAM) and process model of family functioning. Journal of Family Therapy, 22(2), 190-210. https://doi.org/Doi 10.1111/1467-6427.00146

Smith, S. R., \& Soliday, E. (2001). The Effects of Parental Chronic Kidney Disease on the Family. Family Relations, 50(2), 171-177. https://doi.org/10.1111/j.1741-3729.2001.00171.x

Stengel, B., Combe, C., Jacquelinet, C., Briançon, S., Fouque, D., Laville, M., Frimat, L., Pascal, C., Herpe, Y.-E., Deleuze, J.-F., Schanstra, J., Pisoni, R. L., Robinson, B. M., \& Massy, Z. A. (2014). The French Chronic Kidney Disease-Renal Epidemiology and Information Network (CKD-REIN) cohort study. Nephrology, dialysis, transplantation: official publication of the European Dialysis and Transplant Association - European Renal Association, 29(8), 1500-7. 
Stengel, B., Metzger, M., Combe, C., Jacquelinet, C., Briançon, S., Ayav, C., Fouque, D., Laville, M., Frimat, L., Pascal, C., Herpe, Y.-E., Morel, P., Deleuze, J.-F., Schanstra, J. P., Lange, C., Legrand, K., Speyer, E., Liabeuf, S., Robinson, B. M., \& Massy, Z. A. (2019). Risk profile, quality of life and care of patients with moderate and advanced CKD : The French CKD-REIN Cohort Study. Nephrology, Dialysis, Transplantation: Official Publication of the European Dialysis and Transplant Association - European Renal Association, 34(2), 277-286. https://doi.org/10.1093/ndt/gfy058

Szinovacz, M. E. (1983). Using couple data as a methodological tool : The case of marital violence. Journal of Marriage and the Family, 45(3), 633-644. https://doi.org/10.2307/351668

Tutty, L. M. (1995). Theoretical and practical issues in selecting a measure of family functioning. Research on Social Work Practice, 5(1), 80-106. https://doi.org/10.1177/104973159500500107

Untas, A., Rascle, N., Cosnefroy, O., Borteyrou, X., Saada, Y., \& Koleck, M. (2011). Psychometric properties of the French adaptation of the Family Relationship Index (FRI). Encephale, 37(2), 110-118. https://doi.org/10.1016/j.encep.2010.04.008

Untas, A., Thumma, J., Rascle, N., Rayner, H., Mapes, D., Lopes, A. A., Fukuhara, S., Akizawa, T., Morgenstern, H., Robinson, B. M., Pisoni, R. L., \& Combe, C. (2011). The associations of social support and other psychosocial factors with mortality and quality of life in the dialysis outcomes and practice patterns study. Clinical journal of the American Society of Nephrology : CJASN, 6(1), 142-52.

Van De Schoot, R., Schmidt, P., De Beuckelaer, A., Lek, K., \& Zondervan-Zwijnenburg, M. (2015). Editorial: Measurement Invariance. Frontiers in Psychology, 6. https://doi.org/10.3389/fpsyg.2015.01064

Vandenberg, R. J., \& Lance, C. E. (2000). A Review and Synthesis of the Measurement Invariance Literature : Suggestions, Practices, and Recommendations for Organizational Research. Organizational Research Methods, 3(1), 4-70. https://doi.org/10.1177/109442810031002

Wilson-Genderson, M., Pruchno, R. A., \& Cartwright, F. P. (2009). Effects of Caregiver Burden and Satisfaction on Affect of Older End-Stage Renal Disease Patients and Their Spouses. Psychology and Aging, 24(4), 955-967. https://doi.org/10.1037/a0017368 
Table 1. Baseline characteristics of study participants

\begin{tabular}{|c|c|c|c|c|}
\hline & $\begin{array}{l}\text { Whole } \\
\text { sample }\end{array}$ & $\begin{array}{l}\text { Patients who did } \\
\text { not complete the } \\
\text { FRI }\end{array}$ & $\begin{array}{l}\text { Participants } \\
\text { who completed } \\
\text { the FRI }\end{array}$ & $\mathbf{p}$ \\
\hline $\mathbf{N}$ & 3033 & 991 & 2042 & \\
\hline Age (mean, standard-deviation) ${ }^{1}$ & $66.8(12.9)$ & $68.7(12.7)$ & $65.9(12.9)$ & $* * *$ \\
\hline Men $(\%)^{1}$ & 65.3 & 59.2 & 68.3 & $* * *$ \\
\hline Marital status $(\%)^{2}$ & & & & $* * *$ \\
\hline Single & 9.2 & 8.0 & 9.8 & $-{ }^{3}$ \\
\hline Married/Civil Union & 57.9 & 35.7 & 68.6 & $* 3$ \\
\hline Widow-er & 10.7 & 13.3 & 9.5 & $* 3$ \\
\hline Divorced & 9.5 & 6.2 & 11.1 & -3 \\
\hline Missing Data & 12.7 & 36.8 & 1.0 & \\
\hline Living condition (\%) ${ }^{2}$ & & & & $* * *$ \\
\hline Alone & 19.3 & 19.6 & 19.1 & $* 3$ \\
\hline With at least one relative & 64.7 & 39.3 & 77.0 & $* 3$ \\
\hline Other & 1.3 & 1.3 & 1.2 & -3 \\
\hline Missing Data & 14.8 & 39.9 & 2.6 & \\
\hline Education $(\%)^{1}$ & & & & $* * *$ \\
\hline$<9$ years & 35.7 & 49.1 & 29.2 & $* 3$ \\
\hline $9-12$ years & 38.4 & 32.4 & 41.3 & $* 3$ \\
\hline$>12$ years & 24.2 & 16.8 & 27.8 & $* 3$ \\
\hline Missing Data & 1.7 & 1.7 & 1.7 & \\
\hline \multicolumn{5}{|l|}{ Professional status $(\%)^{1}$} \\
\hline Active & 16.9 & 10.5 & 20.0 & $* * *$ \\
\hline Invalidity & 9.4 & 10.8 & 8.7 & $* * *$ \\
\hline Sick leave & 2.8 & 2.8 & 2.8 & - \\
\hline Retired & 63.8 & 52.4 & 69.3 & $* * *$ \\
\hline CKD stage $(\%)^{1}$ & & & & $*$ \\
\hline $2 / 3$ & 55.1 & 52.1 & 56.5 & \\
\hline $4 / 5$ & 44.9 & 47.9 & 43.5 & \\
\hline Diabetes $(\%)^{1}$ & 42.9 & 49.0 & 39.9 & $* * *$ \\
\hline $\begin{array}{l}\text { Self-administred questionnaire } \\
\text { completion }^{2}\end{array}$ & & & & $* * *$ \\
\hline Completion without help (\%) & 67.7 & 40.1 & 81.1 & \\
\hline Completion with help (\%) & 17.9 & 21.3 & 16.3 & \\
\hline ...from a family member (\%) & 90.2 & 87.2 & 92.2 & - \\
\hline
\end{tabular}


Table 2. Comparison between participants who did not complete the questionnaire with help and those who did

\begin{tabular}{|c|c|c|c|}
\hline & $\begin{array}{l}\text { Participants who } \\
\text { completed the } \\
\text { questionnaire } \\
\text { without help }\end{array}$ & $\begin{array}{l}\text { Participants who } \\
\text { completed the } \\
\text { questionnaire with } \\
\text { help }\end{array}$ & $\mathbf{p}$ \\
\hline $\mathbf{N}$ & 1657 & 332 & \\
\hline Age (mean, standard-deviation) ${ }^{1}$ & $65.3(12.9)$ & $69.3(11.7)$ & $* * *$ \\
\hline $\operatorname{Men}(\%)^{1}$ & $67.0 \%$ & $75.6 \%$ & $* *$ \\
\hline Marital status $(\%)^{2}$ & & & $*$ \\
\hline Single & $10.1 \%$ & $6.6 \%$ & $* 3$ \\
\hline Married/Civil Union & $67.6 \%$ & $75.6 \%$ & $* 3$ \\
\hline Widow-er & $9.4 \%$ & $10.2 \%$ & $* 3$ \\
\hline Divorced & $11.9 \%$ & $7.5 \%$ & -3 \\
\hline Missing Data & $1.0 \%$ & $0.0 \%$ & \\
\hline Living condition (\%) ${ }^{2}$ & & & $*$ \\
\hline Alone & $20.0 \%$ & $14.5 \%$ & $* 3$ \\
\hline With at least one relative & $76.0 \%$ & $83.7 \%$ & $* 3$ \\
\hline Other & $1.3 \%$ & $0.9 \%$ & -3 \\
\hline Missing Data & $2.7 \%$ & $0.9 \%$ & \\
\hline Education $(\%)^{1}$ & & & $* * *$ \\
\hline$<9$ years & $25.5 \%$ & $45.5 \%$ & $* 3$ \\
\hline $9-12$ years & $41.3 \%$ & $42.2 \%$ & -3 \\
\hline$>12$ years & $31.3 \%$ & $11.4 \%$ & $* 3$ \\
\hline Missing Data & $1.9 \%$ & $0.9 \%$ & \\
\hline \multicolumn{4}{|l|}{ Professional status $(\%)^{1}$} \\
\hline Active & $22.1 \%$ & $9.0 \%$ & $* * *$ \\
\hline Invalidity & $7.8 \%$ & $14.2 \%$ & $* *$ \\
\hline Sick leave & $2.8 \%$ & $2.4 \%$ & - \\
\hline Retired & $67.3 \%$ & $79.5 \%$ & $* * *$ \\
\hline CKD stage $(\%)^{1}$ & & & - \\
\hline $2 / 3$ & $57.8 \%$ & $52.4 \%$ & \\
\hline $4 / 5$ & $42.2 \%$ & $47.6 \%$ & \\
\hline Diabetes (\%) ${ }^{1}$ & $37.5 \%$ & $53.6 \%$ & $* * *$ \\
\hline
\end{tabular}


Table 3. Sensibility analysis of the items

\begin{tabular}{cccc}
\hline Item & Subscale & Kurtosis & Skewness \\
\hline 1 & Cohesion & 1.96 & 1.50 \\
2 & Expression & -0.81 & 0.22 \\
3 & Conflict & 1.08 & -1.25 \\
4 & Cohesion & 0.89 & -1.24 \\
5 & Expression & 0.96 & -1.24 \\
6 & Conflict & -0.43 & 0.57 \\
7 & Cohesion & 0.92 & 0.71 \\
8 & Expression & -0.71 & 0.48 \\
9 & Conflict & 16.42 & -3.80 \\
10 & Cohesion & 2.65 & 1.64 \\
11 & Expression & 0.04 & 0.85 \\
12 & Conflict & -0.15 & 0.76 \\
\hline
\end{tabular}


Table 4. Results of the confirmatory factor analyses and reliabilities

\begin{tabular}{|c|c|c|c|c|c|c|c|c|c|c|c|c|c|c|}
\hline \multirow{2}{*}{ Models } & \multirow{2}{*}{$N$} & \multicolumn{3}{|c|}{ Internal consistency $\alpha$ (AVE) } & \multicolumn{10}{|c|}{ Confirmatory factor analysis } \\
\hline & & Coh. & Exp. & Conf. & $\mathrm{CFI}$ & AGFI & GFI & TLI & $\mathrm{NFI}$ & RMSEA & SRMR & $\mathrm{Chi}^{2}$ & Df & $\mathrm{Chi}^{2} / \mathrm{Df}$ \\
\hline Whole sample & 1657 & $0.68(0.39)$ & $0.53(0.31)$ & $0.70(0.45)$ & 0,922 & 0,928 & 0,958 & 0,890 & 0,915 & 0,078 & 0,047 & 350,731 & 32 & 10,96034 \\
\hline \multicolumn{15}{|l|}{ Gender } \\
\hline Women & 547 & $0.67(0.38)$ & $0.63(0.38)$ & $0.73(0.44)$ & 0,934 & 0,922 & 0,955 & 0,908 & 0,915 & 0,074 & 0,047 & 126,873 & 32 & 3,964781 \\
\hline Men & 1110 & $0.68(0.39)$ & $0.46(0.28)$ & $0.68(0.43)$ & 0,916 & 0,923 & 0,955 & 0,881 & 0,905 & 0,079 & 0,050 & 253,068 & 32 & 7,908375 \\
\hline \multicolumn{15}{|l|}{ Living condition } \\
\hline Living alone & 331 & $0.74(0.50)$ & $0.62(0.44)$ & $0.65(0.38)$ & 0,913 & 0,881 & 0,931 & 0,877 & 0,887 & 0,092 & 0,058 & 122,4 & 32 & 3,825 \\
\hline With at least one relative & 1260 & $0.65(0.33)$ & $0.48(0.27)$ & $0.72(0.47)$ & 0,928 & 0,938 & 0,964 & 0,899 & 0,918 & 0,071 & 0,044 & 234,528 & 32 & 7,329 \\
\hline \multicolumn{15}{|l|}{ Age (years) } \\
\hline$\leq 50$ & 231 & $0.67(0.38)$ & $0.60(0.39)$ & $0.75(0.53)$ & 0,881 & 0,860 & 0,918 & 0,832 & 0,841 & 0,100 & 0,073 & 105,859 & 32 & 3,308094 \\
\hline $51-65$ & 485 & $0.70(0.42)$ & $0.54(0.32)$ & $0.70(0.45)$ & 0,941 & 0,926 & 0,957 & 0,917 & 0,917 & 0,068 & 0,048 & 103,295 & 32 & 3,227969 \\
\hline $66-80$ & 781 & $0.67(0.38)$ & $0.47(0.29)$ & $0.68(0.42)$ & 0,904 & 0,908 & 0,947 & 0,865 & 0,890 & 0,086 & 0,054 & 217,079 & 32 & 6,783719 \\
\hline$>80$ & 160 & $0.64(0.35)$ & $0.50(0.33)$ & $0.65(0.37)$ & 0,915 & 0,871 & 0,925 & 0,881 & 0,851 & 0,081 & 0,065 & 65,243 & 32 & 2,038844 \\
\hline \multicolumn{15}{|l|}{ Education level (years) } \\
\hline$\leq 9$ & 422 & $0.63(0.33)$ & $0.40(0.24)$ & $0.60(0.33)$ & 0,881 & 0,895 & 0,939 & 0,832 & 0,852 & 0,089 & 0,060 & 138,192 & 32 & 4,31850 \\
\hline $10-12$ & 684 & $0.70(0.38)$ & $0.56(0.32)$ & $0.69(0.43)$ & 0,919 & 0,919 & 0,953 & 0,886 & 0,903 & 0,079 & 0,047 & 168,224 & 32 & 5,25700 \\
\hline$>12$ & 520 & $0.70(0.44)$ & $0.57(0.39)$ & $0.78(0.57)$ & 0,930 & 0,907 & 0,946 & 0,901 & 0,912 & 0,083 & 0,060 & 146,998 & 32 & 4,593688 \\
\hline \multicolumn{15}{|l|}{ Diabetes } \\
\hline Yes & 621 & $0.70(0.41)$ & $0.46(0.28)$ & $0.63(0.37)$ & 0,924 & 0,918 & 0,952 & 0,893 & 0,905 & 0,076 & 0,051 & 147,56 & 32 & 4,61125 \\
\hline No & 1031 & $0.67(0.37)$ & $0.57(0.35)$ & $0.74(0.51)$ & 0,923 & 0,924 & 0,956 & 0,891 & 0,912 & 0,079 & 0,050 & 235,868 & 32 & 7,370875 \\
\hline
\end{tabular}




\section{CKD stage}

Stages $2 / 3$

Stages $4 / 5$
$958 \quad 0.68(0.39) \quad 0.50(0.29) \quad 0.73(0.47)$

699 $\begin{array}{llllll}0,917 & 0,923 & 0,955 & 0,884 & 0,906 & 0,079\end{array}$

$0,927 \quad 0,921-0,954 \quad 0,897-0,911$

0,076
$225,308 \quad 32 \quad 7,040875$

$050 \quad 159,613 \quad 32 \quad 4,987906$ 
Table 5. Model comparisons

\begin{tabular}{|c|c|c|c|c|c|c|c|c|c|}
\hline \multicolumn{10}{|c|}{ Gender } \\
\hline & Df & $\mathrm{AIC}$ & $\mathrm{BIC}$ & Chi-square & $\Delta$ Chi-square & $\Delta \mathrm{Df}$ & $p$ & $\Delta \mathrm{CFI}$ & $\triangle \mathrm{RMSEA}$ \\
\hline Configural invariance & 64 & 35629 & 35986 & 379.94 & & & & & \\
\hline Metric invariance & 71 & 35625 & 35944 & 390.26 & 10.322 & 7 & & 0.001 & 0.004 \\
\hline Scalar invariance & 78 & 35636 & 35918 & 415.82 & 25.556 & 7 & $* * *$ & 0.005 & 0.001 \\
\hline Strict invariance & 81 & 35646 & 35911 & 431.08 & 15.265 & 3 & $* *$ & 0.003 & 0.000 \\
\hline \multicolumn{10}{|c|}{ Living condition } \\
\hline & Df & AIC & $\mathrm{BIC}$ & Chi-square & $\Delta$ Chi-square & $\Delta \mathrm{Df}$ & $p$ & $\Delta \mathrm{CFI}$ & $\triangle \mathrm{RMSEA}$ \\
\hline Configural invariance & 96 & 34302 & 34835 & 408.51 & & & & & \\
\hline Metric invariance & 110 & 34298 & 34756 & 432.62 & 24.112 & 14 & $*$ & 0.003 & 0.004 \\
\hline Scalar invariance & 124 & 34307 & 34689 & 469.00 & 36.373 & 14 & $* * *$ & 0.006 & 0.002 \\
\hline \multicolumn{9}{|c|}{ Age } & 0.003 \\
\hline & Df & AIC & $\mathrm{BIC}$ & Chi-square & $\Delta$ Chi-square & $\Delta \mathrm{Df}$ & $p$ & $\Delta \mathrm{CFI}$ & $\triangle \mathrm{RMSEA}$ \\
\hline Configural invariance & 128 & 35664 & 36378 & 491.48 & & & & & \\
\hline Metric invariance & 149 & 35644 & 36245 & 513.97 & 22.493 & 21 & & 0.000 & 0.006 \\
\hline Scalar invariance & 170 & 35636 & 36123 & 547.29 & 33.318 & 21 & $*$ & 0.003 & 0.004 \\
\hline Strict invariance & 179 & 35665 & 36104 & 595.01 & 47.726 & 9 & $* * *$ & 0.009 & 0.002 \\
\hline \multicolumn{10}{|c|}{ Education level } \\
\hline & Df & AIC & $\mathrm{BIC}$ & Chi-square & $\Delta$ Chi-square & $\Delta \mathrm{Df}$ & $\mathrm{p}$ & $\Delta \mathrm{CFI}$ & $\triangle \mathrm{RMSEA}$ \\
\hline Configural invariance & 96 & 34881 & 35415 & 453.41 & & & & & \\
\hline Metric invariance & 110 & 34869 & 35328 & 469.83 & 16.413 & 14 & & 0.001 & 0.005 \\
\hline Scalar invariance & 124 & 34899 & 35282 & 528.17 & 58.344 & 14 & $* * *$ & 0.011 & 0.000 \\
\hline Strict invariance & 130 & 34908 & 35259 & 548.87 & 20.694 & 6 & $* *$ & 0.003 & 0.000 \\
\hline \multicolumn{10}{|c|}{ Diabetes } \\
\hline & Df & AIC & $\mathrm{BIC}$ & Chi-square & $\Delta$ Chi-square & $\Delta \mathrm{Df}$ & $p$ & $\Delta \mathrm{CFI}$ & $\triangle \mathrm{RMSEA}$ \\
\hline Configural invariance & 64 & 35505 & 35862 & 383.43 & & & & & \\
\hline Metric invariance & 71 & 35507 & 35826 & 398.69 & 15.2671 & 7 & $*$ & 0.002 & 0.003 \\
\hline Scalar invariance & 78 & 35515 & 35796 & 421.19 & 22.4951 & 7 & $* *$ & 0.004 & 0.002 \\
\hline Strict invariance & 81 & 35511 & 35777 & 423.45 & 2.26160 & 3 & & 0.000 & 0.001 \\
\hline \multicolumn{10}{|c|}{ CKD stage } \\
\hline
\end{tabular}




\begin{tabular}{lccccccccc}
\hline & Df & AIC & BIC & Chi-square & $\Delta$ Chi-square & $\Delta$ Df & $p$ & $\Delta$ CFI & $\Delta$ RMSEA \\
Configural invariance & 64 & 35704 & 36061 & 384.92 & & & & & \\
Metric invariance & 71 & 35694 & 36013 & 388.42 & 3.4986 & 7 & - & 0.001 & 0.004 \\
Scalar invariance & 78 & 35692 & 35793 & 400.27 & 11.8561 & 7 & - & 0.001 & 0.003 \\
Strict invariance & 81 & 35690 & 35955 & 404.32 & 4.04980 & 3 & - & 0.000 & 0.001 \\
\hline
\end{tabular}

